\title{
O Que Determina a Satisfação dos Turistas Internacionais no Brasil?
}

\author{
What Causes International Tourists' Satisfaction in Brazil?
}

\author{
Qué Determina la Satisfacción de los Turistas Internacionales en Brasil?
}

Glauber Eduardo de Oliveira Santos ${ }^{1}$

\section{Resumo}

O presente trabalho identifica e mensura os determinantes da satisfação dos turistas internacionais no Brasil. Para tanto, são analisadas as opiniões de mais de 242 mil turistas estrangeiros que visitaram o país entre 2004 e 2012. O tratamento das informações é feito através do uso de um modelo probit ordinal, o qual oferece estimativas altamente confiáveis. As variações na satisfação geral foram controladas pelas características individuais dos turistas, incluindo idade, gênero, nível de escolaridade, renda familiar, país de residência, visitas anteriores ao Brasil e motivo da viagem. Avaliações de dezesseis aspectos específicos do produto turístico brasileiro foram utilizadas como variáveis explicativas da satisfação geral dos turistas. Constatou-se que uma boa avaliação da hospitalidade do povo brasileiro é o aspecto mais relevante para a satisfação geral dos turistas com a viagem. Dentre os elementos mais importantes estão ainda hospedagem, diversão noturna, segurança, limpeza pública, aeroportos, preços, informação turística e gastronomia.

Palavras-chave: Satisfação do Turista; Demanda Turística; Turismo Receptor; Turismo no Brasil; Probit Ordinal.

\begin{abstract}
This study identifies and measures the determinants of international tourists' satisfaction in Brazil. It analyzes the opinions of more than 242 thousand inbound tourists who visited the country from 2004 to 2012. Data analysis is conducted through the use of an ordinal probit model, which provides highly accurate estimates. Variations of the overall tourists' satisfaction are controlled by individual tourists' characteristics, such as age, gender, level of education, household income, country of residence, previous visits to Brazil and the purpose of the trip. Evaluations of sixteen specific aspects of the Brazilian tourism product were used to explain tourists' overall satisfaction. Results show that a good opinion of the Brazilian hospitality is the most relevant aspect to the overall tourists' satisfaction. Other aspects among the most important are accommodation, nightlife, public safety, public sanitation, airports, prices, tourist information and gastronomy.
\end{abstract}

Keywords: Tourist satisfaction; Tourism demand; Inbound tourism; Tourism in Brazil; Ordinal probit.

\footnotetext{
${ }^{1}$ Bacharel em Turismo pela Escola de Comunicações e Artes da Universidade de São Paulo (ECA-USP). Mestre em Ciências da Comunicação na linha de pesquisa de Turismo e Lazer pela ECA-USP. Doutorando em Economia do Turismo e do Meio Ambiente na Universidade das Ilhas Baleares, Espanha. Professor efetivo do Instituto Federal de São Paulo (IFSP) e pesquisador da Fundação Instituto de Pesquisas Econômicas (FIPE) da USP. Brasil. glaubereduardo@gmail.com
} 


\section{Resumen}

El presente trabajo identifica y mensura los determinantes de la satisfacción de los turistas internacionales en Brasil. Para tanto, son analizadas opiniones de más de 242 mil turistas extranjeros que visitaran el país entre 2004 y 2012. El tratamiento de las informaciones utiliza un modelo probit ordinal, lo cual ofrece estimativas altamente confiables. Las variaciones en la satisfacción general fueron controladas por las características individuales de los turistas, incluyendo edad, genero, nivel de escolaridad, renta familiar, país de residencia, visitas anteriores al Brasil y motivo de la viaje. Evaluaciones de dieciséis aspectos específicos del producto turístico brasileño fueron utilizadas como variables explicativas de la satisfacción general de los turistas. Se constató que una buena evaluación de la hospitalidad del pueblo brasileño es el aspecto más relevante para la satisfacción general de los turistas con el viaje. Entre los elementos más importantes están aún hospedaje, diversión nocturna, seguridad, limpieza publica, aeropuertos, precios, información turística y gastronomía.

Palabras Clave: Satisfacción del turista. Demanda turística. Turismo receptor. Turismo en Brasil. Probit ordinal.

\section{Introdução}

O turismo internacional é uma atividade altamente competitiva. Grande parte dos países tem destinado esforços substanciais para a atração de parte dos 980 milhões de turistas que realizam viagens internacionais anualmente em todo o mundo (UNWTO, 2012). O crescimento da demanda e da competição entre países tem levado ao desenvolvimento de estratégias cada vez mais complexas. Uma vez que os recursos disponíveis para o investimento em ações de estruturação e marketing dos destinos turísticos são limitados, o direcionamento estratégico dos esforços se torna fundamental. É preciso saber como e onde investir os recursos disponíveis a fim de ampliar os benefícios alcançados com a atração dos fluxos internacionais de turistas.

O retorno sobre o investimento na estruturação e marketing do destino turístico depende essencialmente do mercado consumidor. Investimentos que melhorem o destino sob o ponto de vista do turista são capazes de ampliar a demanda e, consequentemente, aumentarem também os benefícios obtidos. Nesse contexto, os gestores de turismo se deparam frequentemente com dilemas na destinação dos recursos. É mais eficiente investir recursos nos aeroportos ou na capacitação de recursos humanos? Priorizar a estruturação de atrativos ou o aprimoramento dos serviços? Melhores estradas ou sinalização turística? 
Para responder essas questões é fundamental ter informações confiáveis sobre as preferências dos turistas. O presente artigo busca contribuir nesse sentido, identificando e mensurando os determinantes da satisfação dos turistas internacionais no Brasil. Para tanto, são analisadas as opiniões de mais de 242 mil turistas estrangeiros que visitaram o Brasil entre 2004 e 2012. O tratamento das informações é feito através do uso de um modelo probit ordinal, o qual se ajusta adequadamente aos dados e oferece estimativas altamente confiáveis sobre as questões tratadas.

Este estudo pode ser considerado uma atualização e consolidação de outro estudo realizado com objetivos similares e utilizando a mesma fonte de dados desenvolvido por Santos, Vassallo e Rabahy (2009). Em comparação com o trabalho anterior, o presente estudo apresenta duas contribuições principais. Em primeiro lugar, foram acrescentadas à base de dados informações sobre anos anteriores e posteriores, ampliando em mais de $370 \%$ o total de observações utilizadas e, consequentemente, fornecendo estimativas mais confiáveis. Em segundo lugar, a técnica estatística utilizada no presente estudo é mais adequada à natureza da variável dependente, também fornecendo resultados mais confiáveis, além de simplificar substancialmente a interpretação destes.

\section{Revisão Teórica}

Uma vez que produção e consumo do turismo são concomitantes, a demanda turística por um destino é resultado da expectativa de satisfação. Turistas decidem viajar a um local porque esperam satisfazer suas necessidades e desejos. Portanto, a informação sobre o destino é um elemento essencial para a efetivação da demanda turística. A simples oferta, sem que a informação sobre ela atingisse o consumidor, seria absolutamente inútil.

Diferentes canais de informação influenciam a demanda turística. A mídia e a publicidade possuem papéis extremamente relevantes. Mas além desses, as decisões de viagem também sofrem influência interpessoal e das experiências prévias com o destino. Estudos apontam que a influência interpessoal, incluindo a propaganda boca-a-boca, tem importância excepcional no turismo (LITVIN; GOLDSMITH; PAN, 2008; PREBENSEN; SKALLERUD; CHEN, 2010). Historicamente, amigos e parentes constituíram a principal fonte de informação para a visita ao Brasil por turistas estrangeiros, tendo essa fonte sido ultrapassada pela Internet 
somente em 2010, mas ainda mantendo a segunda posição nesse ranking (MINISTÉRIO DO TURISMO, 2012). A importância das experiências prévias com o destino também é destacada no turismo em virtude das altas taxas de retorno dos visitantes. Cerca de dois terços dos turistas internacionais que visitam o Brasil já haviam estado no país anteriormente, ao passo que cerca de $95 \%$ desse fluxo receptivo total prende retornar ao país (MINISTÉRIO DO TURISMO, 2012).

Recomendações a parentes e amigos, intenção de retorno e fidelidade (ou lealdade) são comportamentos pós-compra fortemente influenciados pela satisfação com a experiência de visitação (ALEGRE; CLADERA, 2009; BOSQUE; MARTÍN; COLLADO, 2006; CHINGFU; ODONCHIMEG, 2010; GALLARZA; SAURA, 2006; HYUN; PERDUE, 2010; JANG; FENG, 2007; PRAYAG, 2008; YOON; UYSAL, 2005). Portanto, satisfazer os turistas pode ser considerado um objetivo intermediário para o aumento da demanda futura na medida em que maiores níveis de satisfação implicam em mais propaganda boca-a-boca e maior fidelidade do turista. Nesse contexto, satisfazer os visitantes não é apenas uma questão de orgulho dos empresários e gestores públicos do destino, mas também uma estratégia de mercado.

A satisfação dos visitantes de destinos turísticos é um assunto particularmente complexo em virtude dos múltiplos aspectos que compõem a oferta do destino. A experiência do turista que visita um destino qualquer não é composta apenas das atrações ou hospedagem, mas também de uma infinidade de outros elementos tangíveis e intangíveis, objetivos e subjetivos, mensuráveis e imensuráveis. Diversos estudos buscam identificar os determinantes da satisfação dos turistas. Características demográficas e socioeconômicas constituem uma importante categoria de variáveis explicativas da satisfação (HUI; WAN; HO, 2007; MENDES et al., 2010; TURNER; REISINGER; McQUILKEN; 2002). Contudo, a comparação dos resultados de diferentes pesquisas mostra que os efeitos dessas variáveis são específicos para cada caso. Turistas com as mesmas características tendem a ter níveis de satisfação diferentes de acordo com o tipo de destino visitado. Algumas das variáveis individuais mais comumente utilizadas em estudos de satisfação são local de residência, idade, gênero, nível educacional, renda, motivação e experiências anteriores com o destino (CRAGGS; SCHOFIELD, 2011; HASEGAWA, 2010; MARCUSSEN, 2011; MCDOWALL; 
MA, 2010; MENEZES; VIEIRA; CARVALHO, 2009; OZTURK; HANCER, 2008; PREBENSEN; SKALLERUD; CHEN, 2012; TASCI; BOYLU, 2010).

A satisfação geral dos turistas com a viagem também pode ser explicada a partir da satisfação com diferentes componentes da experiência turística (CHI; QU, 2008; EKINCI, 2003; PETRICK; BACKMAN, 2002). Marcussen (2011) e Aktaş, Çevirgen e Toker (2010), por exemplo, apontam que a satisfação com o meio de acomodação é o determinante mais forte da satisfação geral. Já para Hasegawa (2010), os principais determinantes da satisfação geral com a viagem são as satisfações com a paisagem e a alimentação. Ainda, Campo-Martínez e Garau-Vadell (2010) estimam que a satisfação com a paisagem, praias e clima constitui o principal fator da satisfação geral. Para estes autores, a sequência de fatores mais relevantes segue com qualidade ambiental do destino, hospitalidade e serviços de alimentação, entretenimento e compras. Satisfação com os níveis de higiene e segurança também influenciam a satisfação geral dos turistas (TASCI; BOYLU, 2010). É interessante notar que Alegre e Garau (2010) apontam que a satisfação com aspectos positivos componentes da experiência turística influenciam a satisfação geral de forma assimétrica em relação à insatisfação com aspectos negativos.

No Brasil, diversos estudos abordam a satisfação dos turistas em relação a diferentes tipos de produtos e estabelecimentos, como meios de hospedagem (FERREIRA, 2004; GONZÁLEZ, 2005; JOÃO; MERLO; MORGADO, 2010; LEMOS, 2001; MELO; FARIAS, 2003; MINCIOTTI; SANTOLIA; KASPAR, 2008; REIS NETO; GONÇALVES FILHO; CABRAL, 2009; VEIGA; FARIAS, 2005), agências de viagens (OLIVEIRA; IKEDA, 2002; SOUTO; OLIVEIRA, 2007), serviços de alimentação (ARAÚJO; MIRANDA JÚNIOR, 2011; CHAGAS; MARQUES JÚNIOR; RIBEIRO, 2011; MENEZES, 2009; SALAZAR; FARIAS; LUCIAN, 2008, 2009; SILVA; MEDEIROS; COSTA, 2009), eventos (ZUCCO; MAGALHÃES; MORETTI, 2010), terminais rodoviários (BURKOWSKI, 2005), serviços de transporte turístico (BANDEIRA; ARIOTTI; MARINS, 2008), artesanato e souvenires (VASCONCELOS, 2007) e canais de distribuição de passagens aéreas (BRASIL, 2006). Utilizando uma perspectiva diferente, Motta e Lima (2007) focam a satisfação dos turistas da terceira idade com relação à prestação de serviços turísticos em geral.

Poucos estudos brasileiros se centram na satisfação de turistas com o destino visitado. Rodrigues (2003) estudou a satisfação dos turistas que visitam Natal (RN). Campos e Filetto 
(2011) realizaram um estudo exploratório-descritivo da satisfação dos visitantes da Serra do Cipó (MG). Cerqueira e Freire (2010) realizaram um estudo sobre a satisfação dos turistas que visitam Ilhéus (BA) e utilizaram análise fatorial para construir categorias de análise.

Chagas e Marques Júnior (2010) realizaram um estudo criterioso dos turistas que visitam Natal (RN) a partir de uma amostra de 400 entrevistados. Esse estudo analisou a influência da satisfação com de diversos aspectos específicos sobre a satisfação geral e a fidelização dos turistas. Inicialmente, a satisfação com aspectos específicos foi agrupada em nove categorias através do processo de análise fatorial exploratória. Essas categorias foram utilizadas como variáveis explicativas de regressões múltiplas independentes para cada uma das variáveis de interesse (satisfação e fidelização). Os resultados apontaram que a satisfação dos turistas é determinada pela imagem do destino e pela satisfação com os equipamentos do hotel, hospitalidade, praias e facilidades, acesso ao hotel, entretenimento e atrativos, serviços de transportes e equipamentos públicos.

Um estudo similar foi desenvolvido por Machado e Gosling (2010) com foco na satisfação, lealdade e propaganda boca-a-boca dos turistas de Ouro Preto (MG). Esse estudo utilizou uma amostra de 343 observações e também fez uso da análise fatorial exploratória para reduzir o número de variáveis explicativas. No entanto, a técnica estatística utilizada para a modelagem final das variáveis de interesse foi o modelo de equações estruturais. Essa técnica é especialmente útil quando há mais de uma variável endógena no modelo, como no caso em que satisfação e lealdade são concomitantemente modeladas. Os resultados obtidos apontaram que a satisfação geral é causada pela satisfação com a herança cultural, informações turísticas, preço e atrativos culturais. $O$ estudo apontou também que a satisfação geral antecede a lealdade e a propaganda boca-a-boca.

Por fim, Santos, Vassallo e Rabahy (2009) estudaram a satisfação dos turistas estrangeiros que visitam o Brasil utilizando uma amostra com mais de 51 mil entrevistas proveniente da mesma fonte de dados utilizada no presente estudo. Modelos separados foram utilizados para a satisfação das expectativas dos turistas e para suas intenções de retorno ao país. O modelo binomial logit foi utilizado para a análise dos dados. Os resultados apontaram que os aspectos mais relevantes para a satisfação geral dos turistas são hospitalidade, hospedagem, diversão noturna, segurança pública e guias de turismo. 


\section{Análise Empírica}

O presente estudo objetivou analisar os determinantes da satisfação dos turistas estrangeiros que visitam o Brasil. Em particular, buscou-se compreender como a satisfação com diferentes aspectos do produto turístico brasileiro influenciam a satisfação geral dos turistas. A fim de evidenciar as relações entre variáveis explicativas e explicadas, foi utilizada a técnica de modelagem estatística dos dados. A seguir são descritos: a fonte de dados, as variáveis utilizadas, o método de estimação, e os resultados obtidos.

\subsection{Fonte de dados}

Os dados utilizados neste estudo são originários do banco de dados do projeto de Caracterização e Dimensionamento do Turismo Internacional no Brasil desenvolvido pela Fundação Instituto de Pesquisas Econômicas (FIPE) em parceria com o Ministério do Turismo e o Instituto Brasileiro de Turismo (Embratur) desde 2004. Esse projeto visa levantar dados e gerar estatísticas oficiais sobre as características do fluxo turístico receptivo do Brasil a fim de prover informações úteis para a gestão pública e privada do turismo no país.

O levantamento de dados desse projeto é realizado por meio de entrevistas diretas com turistas nos 27 principais portões de entrada do Brasil. Os 15 aeroportos internacionais ${ }^{2}$ incluídos na pesquisa respondem por cerca de $99 \%$ do fluxo aéreo internacional de passageiros no país. Já o fluxo terrestre de turistas é mais disperso, sendo que as 12 fronteiras terrestres $^{3}$ pesquisadas respondem por cerca de $90 \%$ do total no país. A coleta de dados ocorre em quatro etapas anuais realizadas nos meses de Janeiro, Abril, Julho e Outubro. Cada etapa de pesquisa se estende por duas semanas nos pontos de pesquisa com maior fluxo de turistas e uma semana nos demais pontos. As entrevistas são conduzidas em seis diferentes idiomas, a saber: Português, Inglês, Espanhol, Francês, Italiano e Alemão. Desse banco de dados foram utilizadas informações de 242.825 entrevistas realizadas entre 2004 e 2012. Estatísticas descritivas dessa fonte de informações podem ser obtidas na publicação Estudo da demanda turística internacional 2005-2011 (MINISTÉRIO DO TURISMO, 2012)

\footnotetext{
${ }^{2}$ Belém (PA), Belo Horizonte (MG), Brasília (DF), Curitiba (PR), Florianópolis (SC), Fortaleza (CE), Maceió (AL), Manaus (AM), Natal (RN), Porto Alegre (RS), Porto Seguro (BA), Recife (PE), Rio de Janeiro (RJ), Salvador (BA), São Paulo (SP).

${ }^{3}$ Chuí (RS), Corumbá (MS), Dionísio Cerqueira (SC), Epitaciolândia (AC), Foz do Iguaçu (PR) - Ponte Internacional da Amizade e Ponte Tancredo Neves, Jaguarão (RS), Pacaraima (RR), Ponta Porã (MS), Santana do Livramento (RS), São Borja (RS), Uruguaiana (RS).
} 


\subsection{Variáveis utilizadas}

A variável dependente deste estudo é a satisfação das expectativas dos turistas. O questionário utilizado para o levantamento de informações oferecia ao entrevistado quatro alternativas de resposta: superação das expectativas, atendimento pleno, atendimento parcial, e decepção. Portanto, a variável indicativa da satisfação é de natureza ordinal, sendo que as diferentes alternativas formam uma sequência, mas não apresentam cardinalidade.

Cabe destacar a existência de uma pequena disparidade entre a variável coletada e a satisfação geral conforme definida pela literatura específica na medida em que a primeira envolve também as expectativas dos turistas. Porém, não havendo disponibilidade de outra variável mais adequada para a representação da satisfação geral dos turistas, essa foi adotada como variável de interesse do presente estudo.

Cinco conjuntos de variáveis explicativas foram incluídos no modelo. O primeiro conjunto se refere às características dos turistas. A inclusão dessas variáveis no modelo visa captar a variação esperada da satisfação geral dada pelas características pessoais, possibilitando o controle desses aspectos no desenvolvimento da análise central relativa ao efeito da satisfação com aspectos específicos da viagem sobre a satisfação geral. Sete variáveis desta categoria foram utilizadas: idade, gênero, nível de escolaridade, renda familiar, país de residência, visitas anteriores ao Brasil e motivo da viagem. A variável idade ao quadrado também foi introduzida no modelo a fim de permitir uma relação não linear entre satisfação geral e idade do turista. A renda familiar mensal foi mensurada em milhares de dólares, utilizando-se valores constantes de 2010. Além disso, o valor da renda foi transformado em logaritmo natural a fim de levar em consideração a característica estritamente positiva da variável e sua distribuição assimétrica positiva. Os principais países de residência foram identificados por variáveis dummy específicas, enquanto os demais países foram agrupados por continente. Dessa forma, foram destacados os 11 países de onde mais de 100 mil turistas vêm ao Brasil anualmente de acordo com dados do Ministério do Turismo. O número de visitas anteriores ao Brasil foi mensurado na forma logarítmica pelos mesmos motivos apresentados com respeito à renda. Também foi introduzida no modelo uma variável dicotômica indicando os casos nos quais os turistas visitavam o país pela primeira vez. O motivo principal da viagem foi categorizado em sete grupos, incluindo motivações de lazer e não de lazer. 
O segundo e principal conjunto de variáveis explicativas é composto pela avaliação feita pelos turistas com respeito a diferentes características do produto turístico brasileiro. Avaliações de treze aspectos do principal destino brasileiro visitado foram incluídas, a saber: diversão noturna, gastronomia, guias de turismo, hospedagem, informação turística, limpeza pública, preços, restaurantes, segurança pública, serviço de táxi, sinalização turística, sistemas de comunicação, e transporte público. Além dessas, três características gerais do produto turístico brasileiro foram consideradas: aeroporto de saída, rodovias e hospitalidade do povo. Portanto, ao todo foram utilizadas 16 variáveis relativas às avaliações feitas pelos turistas acerca do Brasil. A escala de avaliação de cada um destes itens no banco de dados utilizado era composta por quatro pontos identificados pelos termos muito bom, bom, ruim, e muito ruim. Portanto, essas variáveis também são ordinais, formando uma sequência não cardinal de valores. A inclusão dos níveis de satisfação específicos como variáveis explicativas no modelo estatístico foi feita através de três variáveis dummy para cada aspecto avaliado. Essas dummies foram construídas de forma a representar o efeito incremental entre uma e outra categoria de avaliação. A primeira dummy indica a diferença entre as categorias de avaliação muito ruim e ruim, a segunda dummy indica a diferença entre as categorias ruim e bom, e a terceira aponta a diferença entre bom e muito bom.

O terceiro conjunto de variáveis explicativas visa captar variações nos efeitos das avaliações ocorridas ao longo dos anos. Desta forma, para cada observação, o ano desta foi multiplicado pelo valor de cada variável do segundo grupo a fim de constituir novas variáveis. O uso dessas variáveis de interação entre ano e avaliações torna o modelo capaz de lidar com eventuais tendências dos efeitos. Por exemplo, a preocupação com a segurança pode ter aumentado ao longo dos anos, de forma que turistas que percebem boas condições de segurança tenham se tornado progressivamente mais satisfeitos com a viagem ao Brasil. Nesse caso, o efeito dessa variável explicativa teria crescido ao longo dos anos, de forma que o coeficiente da interação entre ano e avaliação da segurança seria positivo.

Note-se que a própria variação ao longo do tempo das avaliações dos turistas sobre aspectos específicos não é o foco da análise proporcionada pelo terceiro conjunto de variáveis explicativas. Ao longo dos nove anos de pesquisa utilizados neste estudo, as condições do Brasil como destino turístico mudaram, fazendo variar as avaliações dos turistas sobre cada aspecto e, consequentemente, alterando também o nível de satisfação geral desses visitantes. 
No entanto, essas mudanças nas condições dos destinos não alteram necessariamente a relação entre avaliações e satisfação. Em outras palavras, tais mudanças apenas fazem com que o valor observado das variáveis explicativas se altere, sem modificar necessariamente o valor dos parâmetros da função de satisfação. A variabilidade das observações, seja entre indivíduos de um mesmo ano ou de anos distintos, é justamente o fator que permite a análise das relações entre avaliações e satisfação. Portanto, eventuais mudanças nos padrões de avaliação dos aspectos específicos não constituem qualquer problema para a presente análise. Já as mudanças nas preocupações dos turistas podem constituir fonte de distorções das estimativas, sendo estas tratadas por meio do uso das variáveis explicativas do terceiro conjunto.

No quarto conjunto de variáveis foram incluídas dummies que identificam o ano de cada observação. Esse conjunto visa captar eventuais alterações temporais do intercepto da função de satisfação. Variações dessa natureza podem ter ocorrido em razão da omissão de variáveis relevantes cujos valores médios tenham mudado ao longo dos anos. Por exemplo, a satisfação geral dos turistas pode ter variado em razão de mudanças em um aspecto relevante ocorridas entre 2004 e 2012. No entanto, se esse aspecto não foi incluído na análise, as estimativas do modelo podem ser enviesadas. Em particular, as estimativas dos efeitos de outros aspectos cujos valores médios variaram ao longo dos anos podem ser as mais afetadas. Dessa forma, as dummies relativas ao ano servem como instrumento para captar essas eventuais variações do nível de satisfação causadas por variáveis omitidas, solucionando o problema.

Por fim, cabe destacar que o número de respostas em branco em cada aspecto avaliado do produto turístico brasileiro obtido na pesquisa utilizada não é desprezível. Esse fato deve-se não apenas às dificuldades de coleta de campo, mas principalmente à impossibilidade de avaliação por ausência de contato do turista com o elemento a ser avaliado. Desta forma, o quinto conjunto de variáveis explicativas é composto por dummies que representam a ausência de resposta. Essa estratégia foi utilizada a fim de reduzir a perda de informações.

\subsection{Método de estimação}

A variável dependente deste estudo é ordinal, ou seja, trata-se de uma variável qualitativa cujos valores podem ser colocados em ordem. A alternativa atendeu plenamente, por exemplo, indica um nível de satisfação geral superior à alternativa atendeu parcialmente. Esse 
tipo de variável é frequentemente tratado como quantitativa, atribuindo-se valores numéricos para cada alternativa. No entanto, esse tratamento é equivocado já que a diferença no nível de satisfação existente entre duas categorias subsequentes quaisquer não é necessariamente a mesma diferença existente entre duas outras categorias subsequentes. Por exemplo, a diferença entre a superação das expectativas e o atendimento pleno delas não é idêntica à diferença entre o atendimento pleno e o atendimento parcial. Assim, atribuir os valores 1, 2, 3 e 4 para as alternativas em sequência seria tão incorreto quanto atribuir os valores 1, 2, 5 e 90 ou qualquer outra sequência crescente de números.

Santos, Vassallo e Rabahy (2009) trataram o problema da ordinalidade da variável dependente através do processo de dicotomização. Naquele estudo, a variável original com quatro categorias foi simplificada em três variáveis distintas, cada uma com apenas duas categorias. A escala original foi dividida em duas partes utilizando-se os três pontos de corte possíveis. Por exemplo, em uma das alternativas, as duas categorias superiores foram agrupadas sob o título superação ou atendimento pleno das expectativas e as duas outras categorias foram agrupadas sob o título atendimento parcial ou decepção. O modelo estatístico utilizado para analisar as causas dessa variável dicotômica foi o logit binomial. Esse procedimento de dicotomização resultou em dois problemas relevantes. Em primeiro lugar, os autores passaram e ter três variáveis de interesse distintas e acabaram estimando três modelos separados, o que dificultou substancialmente a análise. Além disso, esse processo resultou em perda de informações e sub-aproveitamento do banco de dados disponível, já que algumas categorias distintas se tornaram indiferenciáveis.

O tratamento adequado da variável dependente neste caso parte do pressuposto de que há uma escala contínua oculta que representa a verdadeira satisfação do turista. Nessa escala contínua existem três pontos de corte, os quais dividem a escala oculta em quatro categorias observáveis. No entanto, não se dispõe de qualquer informação a priori sobre a posição dos três pontos de corte. Consequentemente, não se pode tratar a escala como uma variável quantitativa. A técnica estatística mais adequada para modelar essa variável o modelo ordinal.

Nesse modelo, a variável dependente é estimada como uma função linear das variáveis independentes e de um conjunto de pontos de corte. A probabilidade de observar o resultado i corresponde à probabilidade de que a função linear estimada adicionada ao termo de erro 
estocástico esteja entre os pontos de corte que definem a categoria i. De forma genérica, essa função ordinal pode ser descrita como

$$
p(j=i)=p\left(k_{i}-1<\boldsymbol{\beta} \boldsymbol{x}_{\boldsymbol{j}}+u_{j} \leq k_{i}\right)
$$

onde $\mathrm{p}(\mathrm{j}=\mathrm{i})$ é a probabilidade de que a observação $\mathrm{j}$ esteja na categoria $\mathrm{i}, \mathrm{k}_{\mathrm{i}}-1$ e $\mathrm{k}_{\mathrm{i}}$ são os pontos de corte que definem a categoria i, $\mathbf{x}$ é um vetor de variáveis independentes, $\boldsymbol{\beta}$ é um vetor de parâmetros a serem estimados e u é o termo de erro estocástico. A estimação dos parâmetros dessa função pode ser feita através do método da máxima verossimilhança.

A interpretação dos parâmetros $\boldsymbol{\beta}$ desse modelo não pode ser feita diretamente. A fim de facilitar tal interpretação, pode-se reportar os efeitos marginais de cada variável, ou seja, o aumento da probabilidade de satisfação máxima (superação das expectativas) dado pela variação de uma unidade na variável explicativa. Contudo, os efeitos marginais nos modelos ordinais não são constantes, variando de acordo com $\mathbf{x}$. Logo, o efeito marginal de cada variável explicativa pode ser diferente para cada indivíduo. A forma usual de lidar com esse problema é o cálculo dos efeitos marginais de cada variável explicativa para o indivíduo típico da amostra utilizada, isto é, para valores médios de todas as variáveis explicativas.

As distribuições estatísticas mais frequentemente assumidas para o termo de u são a normal e a logística. O uso dessas duas distribuições resulta nos modelos conhecidos como ordinal probit e logit, respectivamente. Ambas alternativas foram testadas no presente estudo, tendo o modelo ordinal probit sido selecionado em virtude de sua superioridade de acordo com a estatística de máxima verossimilhança e com o Critério de Informação de Akaike. Detalhes sobre os modelos ordinais são apresentados por Greene e Hensher (2010).

\subsection{Resultados}

O modelo estimado com os cinco conjuntos de variáveis explicativas resultou em um grande número de coeficientes não significantes. Apesar do enorme banco de dados disponível, $43,8 \%$ dos coeficientes relativos às avaliações dos turistas não foram estimados como significantes ao nível de 5\%. Dentre os coeficientes das interações entre ano e avaliações, a parcela de coeficientes não significantes atingiu $75 \%$. A principal causa da obtenção de estimativas tão ruins foi a multicolinearidade entre as variáveis explicativas do segundo e terceiro conjuntos. A falta de tendência dos efeitos das avaliações sobre a satisfação tornou 
esses dois conjuntos quase colineares, ampliando substancialmente os desvios-padrão das estimativas e gerando um grande número de estimativas não significantes.

Uma vez que não se identificou a existência de tendências nos efeitos, e que a tentativa de estima-las predicou fortemente as demais estimativas, o terceiro conjunto de variáveis explicativas foi excluído do modelo. O resultado foi a obtenção de apenas 14,6\% de coeficientes não significantes relativos às avaliações.

Os coeficientes estimados $(\boldsymbol{\beta})$, desvios-padrão, probabilidade de significância (p-valor) e efeitos marginais ${ }^{4}$ do modelo final são apresentados a seguir. A apresentação é dividida em duas tabelas a fim de facilitar a leitura, sendo a primeira referente aos conjuntos um e quatro das variáveis explicativas, e a segunda tabela referente ao conjunto dois dessas variáveis. Não são apresentados os coeficientes referentes ao quinto grupo de variáveis explicativas em virtude da irrelevância desses valores para fins de análise.

Tabela 1: Estimativas referentes às características dos turistas, ano e constantes

\begin{tabular}{|c|c|c|c|c|}
\hline Variável explicativa & $\boldsymbol{\beta}$ & Desvio-padrão & p-valor & Efeito marginal \\
\hline \multicolumn{5}{|l|}{ Idade } \\
\hline Expoente 1 & $-0,019$ & 0,0011 & 0,00 & $-0,00083$ \\
\hline Expoente 2 & 0,00018 & $1,2 \mathrm{E}-05$ & 0,00 & 0,00 \\
\hline \multicolumn{5}{|l|}{ Gênero } \\
\hline Feminino $^{\dagger}$ & 0,00 & & & \\
\hline Masculino & 0,041 & 0,0052 & 0,00 & 0,0018 \\
\hline \multicolumn{5}{|l|}{ Nível de educação } \\
\hline $\begin{array}{l}\text { Fundamental ou sem } \\
\text { instrução }^{\dagger}\end{array}$ & 0,00 & & & \\
\hline Médio & 0,013 & 0,012 & 0,27 & 0,00057 \\
\hline Superior & $-0,0048$ & 0,012 & 0,68 & $-0,00021$ \\
\hline Pós-graduação & $-0,013$ & 0,013 & 0,32 & $-0,00055$ \\
\hline Renda familiar & $-0,0012$ & 0,0020 & 0,56 & $-5,1 \mathrm{E}-05$ \\
\hline \multicolumn{5}{|l|}{ Local de residência } \\
\hline África ${ }^{\dagger}$ & 0,00 & & & \\
\hline Ásia e Oceania & 0,048 & 0,022 & 0,03 & 0,0021 \\
\hline América Central & 0,13 & 0,032 & 0,00 & 0,0057 \\
\hline América do Norte & & & & \\
\hline
\end{tabular}

\footnotetext{
${ }^{4}$ Calculados para um caso com valores médios em todas as variáveis explicativas.
} 


\begin{tabular}{lcccc}
\hline Variável explicativa & $\boldsymbol{\beta}$ & Desvio-padrão & p-valor & Efeito marginal \\
\hline Estados Unidos & 0,10 & 0,020 & 0,00 & 0,0045 \\
Outros & 0,10 & 0,023 & 0,00 & 0,0045
\end{tabular}

América do Sul

$\begin{array}{lll}\text { Argentina } & 0,38 & 0,021 \\ \text { Chile } & 0,29 & 0,022 \\ \text { Paraguai } & 0,25 & 0,023 \\ \text { Uruguai } & 0,29 & 0,024 \\ \text { Outros } & 0,27 & 0,022\end{array}$

$\begin{array}{lll}0,021 & 0,00 & 0,017 \\ 0,022 & 0,00 & 0,013 \\ 0,023 & 0,00 & 0,011 \\ 0,024 & 0,00 & 0,013 \\ 0,022 & 0,00 & 0,012\end{array}$

Europa

$\begin{array}{lcccc}\text { Alemanha } & 0,16 & 0,022 & 0,00 & 0,0072 \\ \text { Espanha } & 0,22 & 0,022 & 0,00 & 0,010 \\ \text { França } & 0,10 & 0,022 & 0,00 & 0,0043 \\ \text { Inglaterra } & 0,077 & 0,023 & 0,00 & 0,0034 \\ \text { Itália } & 0,14 & 0,022 & 0,00 & 0,0063 \\ \text { Portugal } & 0,22 & 0,022 & 0,00 & 0,00 \\ \quad \text { Outros } & 0,10 & 0,021 & 0,00 & 0,0045 \\ \text { itas anteriores } & & & & \\ \text { Primeira vez no Brasil } & 0,080 & 0,0068 & 0,00 & 0,0035 \\ \text { Número de visitas anteriores } & -0,023 & 0,0027 & 0,00 & -0,0010\end{array}$

\section{Motivo da viagem}

Lazer

Sol e praia
Turismo cultural
Turismo de natureza
Outros

Não lazer

Negócios

Visita a amigos e parentes

Outros

Ano

$$
\begin{aligned}
& 2004 \\
& 2005 \\
& 2006 \\
& 2007 \\
& 2008 \\
& 2009 \\
& 2010 \\
& 2011
\end{aligned}
$$$$
2006
$$$$
2008
$$$$
2010
$$$$
2012
$$

0,00

0,031

0,024

$-0,030$

$-0,10$

$-0,033$

0,0042

0,00

$-0,077$

$-0,054$

0,066

0,079

0,11

0,16

0,15

0,18
0,011

0,010

0,015

0,0078

0,0083

0,014

0,070

0,072

0,072

0,072

0,072

0,072

0,072

0,072
0,01

0,0014

0,01

0,05

0,0011

$-0,0013$

$-0,0044$

$-0,0015$

0,00

0,00019

0,75

0,27

$-0,0034$

0,45

$-0,0024$

0,36

0,0029

0,27

0,0035

0,11

0,0050

0,02

0,0072

0,04

0,0065

0,01 0,0081 


\begin{tabular}{lcccc}
\hline \multicolumn{1}{c}{ Variável explicativa } & $\boldsymbol{\beta}$ & Desvio-padrão & p-valor & Efeito marginal \\
\hline Pontos de corte & & & & \\
Decepção $\rightarrow$ Atend. parcial & 0,56 & 0,11 & \\
Atend. parcial $\rightarrow$ Atend. pleno & 1,72 & 0,11 & \\
Atend. pleno $\rightarrow$ Superação & 3,48 & 0,11 & \\
\hline
\end{tabular}

'grupo de referência

A maioria das variáveis relativas às características dos turistas apresentou coeficientes significantes, indicando que a inclusão destas no modelo é relevante e evita vieses de estimação dos demais coeficientes. Os resultados apontam que jovens e pessoas mais velhas tendem a apresentar maiores níveis de satisfação geral. O menor nível esperado de satisfação geral ocorre para pessoas com 59 anos de idade. Os resultados também apontam que homens tendem a apresentar maiores níveis de satisfação geral do que as mulheres. Com respeito ao nível de escolaridade, não há diferenças significativas entre nenhuma das categorias. A ausência de variações significativas também ocorre com respeito à renda familiar. Em outras palavras, os resultados apontam que essa variável não exerce efeito sobre a satisfação geral dos turistas. Turistas sul-americanos tendem a se satisfazerem mais ao viajar para o Brasil do que aqueles oriundos de outras regiões do mundo. Alguns países da Europa, como Espanha, Portugal, Alemanha e Itália, também tendem a apresentar níveis de satisfação geral relativamente altos. Com respeito às visitas anteriores ao Brasil, as estimativas indicam que quanto maior a experiência do turista com o país, menor é seu grau de satisfação. Por fim, o Brasil se apresenta como um destino turístico com maior capacidade de satisfação de turistas de natureza e turistas culturais. O turismo de praia no país apresenta uma capacidade intermediária de satisfação dos visitantes, ao passo que turistas de negócios e de visita a amigos e parentes tendem a apresentar os menores níveis de satisfação quando visitam o país.

As variáveis dummy que identificam o ano de cada observação não se mostraram significantes. Portanto, a hipótese de omissão de variáveis relevantes cujos valores alteraram significativamente ao longo dos anos foi descartada. Como as interações entre ano e avaliações também foram consideradas irrelevantes, pode-se afirmar que o modelo apresenta grande estabilidade ao longo do tempo, e que a longa série de dados não constituiu empecilho para a estimação dos efeitos analisados. 
Os pontos de corte estimados indicam que aumentar o nível de satisfação do turista é mais difícil para aqueles que já se encontram relativamente satisfeitos. Em outras palavras, transformar um turista decepcionado em parcialmente satisfeito é mais fácil do que transformar um indivíduo parcialmente satisfeito em plenamente satisfeito. $\mathrm{O}$ mesmo ocorre com a parte superior da escala, sendo que transformar um turista plenamente satisfeito em alguém com expectativas superadas é a tarefa mais difícil. 
Tabela 2: Estimativas referentes às avaliações de aspectos específicos

\begin{tabular}{|c|c|c|c|c|c|c|c|c|c|c|c|c|}
\hline \multirow{2}{*}{ Aspecto avaliado } & \multicolumn{3}{|c|}{$\boldsymbol{\beta}$} & \multicolumn{3}{|c|}{ Desvio-padrão } & \multicolumn{3}{|c|}{ p-valor } & \multicolumn{3}{|c|}{ Efeito marginal } \\
\hline & $\mathbf{M R} \rightarrow \mathbf{R}$ & $\mathbf{R} \rightarrow \mathbf{B}$ & $\mathrm{B} \rightarrow \mathrm{MB}$ & $\mathbf{M R} \rightarrow \mathbf{R}$ & $\mathbf{R} \rightarrow \mathbf{B}$ & $\mathbf{B} \rightarrow \mathbf{M B}$ & $\mathbf{M R} \rightarrow \mathbf{R}$ & $\mathbf{M R} \rightarrow \mathbf{R}$ & $\mathbf{M R} \rightarrow \mathbf{R}$ & $\mathbf{M R} \rightarrow \mathbf{R}$ & $\mathbf{M R} \rightarrow \mathbf{R}$ & $\mathbf{M R} \rightarrow \mathbf{R}$ \\
\hline Aeroportos & 0,058 & 0,13 & 0,10 & 0,015 & 0,0079 & 0,0085 & 0,000 & 0,000 & 0,000 & 0,0025 & 0,0059 & 0,0043 \\
\hline Diversão noturna & 0,020 & 0,20 & 0,14 & 0,025 & 0,012 & 0,0072 & 0,421 & 0,000 & 0,000 & 0,00088 & 0,0087 & 0,0061 \\
\hline Gastronomia & $-0,039$ & 0,16 & 0,088 & 0,037 & 0,012 & 0,0057 & 0,289 & 0,000 & 0,000 & $-0,0017$ & 0,0071 & 0,0039 \\
\hline Guias de turismo & $-0,032$ & 0,10 & 0,068 & 0,038 & 0,018 & 0,011 & 0,393 & 0,000 & 0,000 & $-0,0014$ & 0,0042 & 0,0030 \\
\hline Hospedagem & 0,11 & 0,22 & 0,12 & 0,035 & 0,012 & 0,0065 & 0,001 & 0,000 & 0,000 & 0,0050 & 0,010 & 0,0053 \\
\hline Hospitalidade & 0,12 & 0,30 & 0,21 & 0,041 & 0,017 & 0,0053 & 0,003 & 0,000 & 0,000 & 0,0054 & 0,013 & 0,0092 \\
\hline Informação turística & 0,059 & 0,14 & 0,044 & 0,027 & 0,013 & 0,011 & 0,025 & 0,000 & 0,000 & 0,0026 & 0,0062 & 0,0020 \\
\hline Limpeza pública & 0,073 & 0,11 & 0,12 & 0,013 & 0,0067 & 0,0071 & 0,000 & 0,000 & 0,000 & 0,0032 & 0,0050 & 0,0052 \\
\hline Preços & 0,076 & 0,10 & 0,11 & 0,010 & 0,0060 & 0,010 & 0,000 & 0,000 & 0,000 & 0,0033 & 0,0043 & 0,0050 \\
\hline Restaurantes & 0,0026 & 0,10 & 0,052 & 0,032 & 0,012 & 0,0060 & 0,937 & 0,000 & 0,000 & 0,00011 & 0,0046 & 0,0023 \\
\hline Rodovias & 0,059 & 0,059 & 0,046 & 0,010 & 0,0065 & 0,0082 & 0,000 & 0,000 & 0,000 & 0,0026 & 0,0026 & 0,0020 \\
\hline Segurança pública & 0,12 & 0,14 & 0,039 & 0,012 & 0,0070 & 0,0074 & 0,000 & 0,000 & 0,000 & 0,0055 & 0,0064 & 0,0017 \\
\hline Serviço de táxi & 0,037 & 0,066 & 0,0078 & 0,023 & 0,011 & 0,0076 & 0,106 & 0,000 & 0,307 & 0,0016 & 0,0029 & 0,00034 \\
\hline Sinalização turística & 0,030 & 0,088 & 0,033 & 0,013 & 0,0071 & 0,0085 & 0,020 & 0,000 & 0,000 & 0,0013 & 0,0039 & 0,0015 \\
\hline Sistemas de comunicação & 0,061 & 0,072 & $-0,00048$ & 0,012 & 0,0068 & 0,0083 & 0,000 & 0,000 & 0,954 & 0,0027 & 0,0031 & $-2,1 \mathrm{E}-05$ \\
\hline Transporte público & 0,066 & 0,066 & 0,032 & 0,018 & 0,011 & 0,010 & 0,000 & 0,000 & 0,001 & 0,0029 & 0,0029 & 0,0014 \\
\hline
\end{tabular}

$* p<0,05 ; * * p<0,01 ; * * * p<0,001$ 


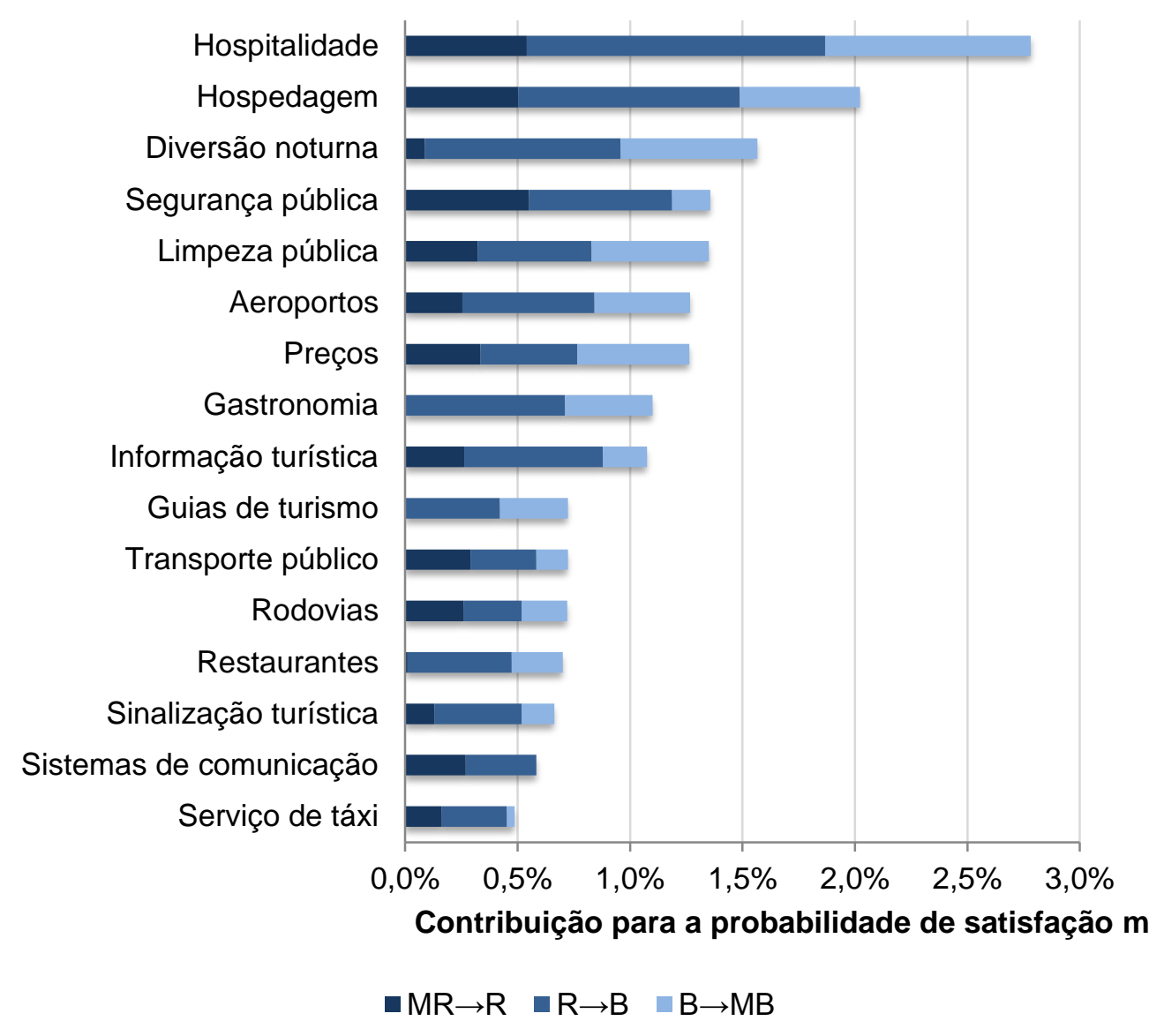

Figura 1: Parâmetros estimados referentes às avaliações de aspectos específicos

Os efeitos marginais apresentados na Tabela 2 são ilustrados na Figura 1 a fim de facilitar a leitura. Nenhum parâmetro negativo estimado é estatisticamente significante, tendo sido inclusive excluídos do gráfico. Isso indica que melhores avaliações dos aspectos particulares da viagem implicam em níveis de satisfação geral iguais ou superiores. Em outras palavras, quanto melhor a avaliação feita pelo turista com respeito aos diferentes elementos envolvidos em sua viagem, maior tende a ser sua satisfação geral.

Os resultados apontam que a hospitalidade é o fator mais importante para a satisfação geral dos turistas dentre os dezesseis aspectos estudados. A alteração da opinião do turista médio sobre a hospitalidade de ruim para bom implica um aumento de 1,3\% na probabilidade de satisfação máxima. Já a mudança da opinião do turista média sobre a hospitalidade de bom para muito bom aumenta a probabilidade de satisfação máxima em 0,9\%. Em segundo lugar 
no ranking de aspectos mais importantes para a satisfação do turista está o meio de hospedagem, sendo este seguido pela diversão noturna, segurança e limpeza pública. Aspectos de importância intermediária são os aeroportos, preços, gastronomia e informação turística. Por fim, os aspectos com menor grau relativo de importância para a satisfação geral dos turistas são serviço de táxi, sistemas de comunicação, sinalização turística, restaurantes e rodovias. Essa escala de importância constitui o principal resultado do presente estudo, indicando exatamente quais aspectos contribuem mais para a satisfação dos turistas internacionais no Brasil.

É interessante notar que o efeito sobre a satisfação geral causado por cada incremento na avaliação dos aspectos específicos não é constante. Para a maior parte dos aspectos específicos, é mais importante saltar da avaliação ruim para a avaliação bom do que passar da avaliação muito ruim para ruim ou de bom para muito bom. Em outras palavras, na maior parte dos casos, as avalições extremas (muito ruim e muito bom) pesam menos do que as avalições moderadas. No entanto, para limpeza pública e preços o salto mais importante é entre bom e muito bom. Portanto, destinos com níveis de limpeza pública e preços apenas bons ainda podem ganhar muito em termos de satisfação geral dos turistas se conseguirem atingir níveis de qualidade muito bons.

\section{Conclusão}

Avaliou-se importância de diferentes aspectos do produto turístico brasileiro sobre a satisfação geral dos turistas internacionais que visitam o país. Para tanto foi utilizado um banco de dados composto por mais de 242 mil entrevistas coletadas entre 2004 e 2012 . O tratamento dos dados foi feito através de um modelo estatístico ordinal probit. Constatou-se que a hospitalidade é o aspecto mais relevante dentre os 16 itens analisados. Dentre os elementos mais importantes estão ainda hospedagem, diversão noturna, segurança, limpeza pública, aeroportos, preços, gastronomia e informação turística.

As informações apresentadas podem ser de grande utilidade para o embasamento de políticas públicas que visem ampliar o nível de satisfação dos turistas com o destino Brasil. Priorizar a melhoria dos aspectos mais relevantes para a satisfação dos turistas estrangeiros pode 
contribuir substancialmente para aumentar a atratividade turística do país e incrementar os benefícios obtidos com essa atividade.

\section{Referências}

AKTAŞ, A.; ÇEVIRGEN, A.; TOKER, B. Tourists' satisfaction and behavioral intentions on destination attributes: an empirical study in Alanya. Tourism Analysis, v. 15, n. 2, p. 243-252, 2010.

ALEGRE, J.; CLADERA, M. Analysing the effect of satisfaction and previous visits on tourist intentions to return. European Journal of Marketing, v. 43, n. 5/6, p. 670-685, 2009.

ALEGRE, J.; GARAU, J. Tourist satisfaction and dissatisfaction. Annals of Tourism Research, v. 37, n. 1, p. 52-73, 2010.

ARAÚJO, G. C. D.; MIRANDA JÚNIOR, L. J. D. Satisfação dos consumidores que frequentam bares. Revista Hospitalidade, v. 8, n. 2, p. 121-146, 2011.

BANDEIRA, R. A. D. M.; ARIOTTI, P.; MARINS, L. M. Análise da qualidade de um serviço de transporte turístico: estudo empírico da linha turismo de Porto Alegre. Turismo Visão e Ação, v. 10, n. 2, p., 2008.

BOSQUE, I. A. R. D.; MARTÍN, H. S.; COLLADO, J. The role of expectations in the consumer satisfaction formation process: empirical evidence in the travel agency sector. Tourism Management, v. 27, n. 3, p. 410-419, 2006.

BRASIL, V. S. O impacto dos canais de distribuição no comportamento de compra no turismo: uma análise das relações entre satisfação, valor e lealdade na aquisição de passagens aéreas através de canais interpessoais e canais baseados em tecnologia. Turismo Visão e Ação, v. 8, n. 3, p. 361-378, 2006.

BURKOWSKI, R. Estudo das Relações Entre a Percepção da Qualidade do Serviço e Hospitalidade na Rodoviária: Um Estudo de Caso no Terminal Rodoviário do Tietê. Dissertação (Mestrado em Hospitalidade) - Universidade Anhembi Morumbi, São Paulo, 2005.

CAMPO-MARTÍNEZ, S.; GARAU-VADELL, J. B. The generation of tourism destination satisfaction. Tourism Economics, v. 16, n. 3, p. 461-475, 2010.

CAMPOS, R. F.; FILETTO, F. Análise do perfil, da percepção ambiental e da qualidade da experiência dos visitantes da Serra do Cipó (MG). Revista Brasileira de Ecoturismo, v. 4, n. 1, p. 6994, 2011.

CERQUEIRA, C. A.; FREIRE, C. F. Fatores determinantes da oferta turística do município de Ilhéus (Bahia) na alta estação do ano de 2007. Turismo em Análise, v. 21, n. 1, p. 47-67, 2010.

CHAGAS, M. M. D.; MARQUES JÚNIOR, S. Análise da relação causal entre imagem, qualidade, satisfação e fidelidade: um estudo sobre a percepção do turista nacional no destino turístico Natal-RN. Turismo em Análise, v. 21, n. 3, p. 494-516, 2010.

CHAGAS, M. M. D.; MARQUES JÚNIOR, S.; RIBEIRO, S. G. D. S. Fatores que afetam a satisfação e fidelidade ao setor de restauração de Natal/RN: uma análise sobre a percepção do turista nacional. Observatório de Inovação do Turismo, v. 6, n. 1, p., 2011.

CHI, C. G.-Q.; QU, H. Examining the structural relationships of destination image, tourist satisfaction and destination loyalty: An integrated approach. Tourism Management, v. 29, n. 4, p. 624-636, 2008. 
CHING-FU, C.; ODONCHIMEG, M. Exploring relationships between Mongolian destination brand equity, satisfaction and destination loyalty. Tourism Economics, v. 16, n. 4, p. 981-994, 2010.

CRAGGS, R.; SCHOFIELD, P. The Quays in Salford: an analysis of visitor perceptions, satisfaction and behavioural intention. International Journal of Tourism Research, v. 13, n. 6, p. 583-599, 2011.

EKINCI, Y. An investigation of the determinants of customer satisfaction. Tourism Analysis, v. 8, n. 2-4, p. 197-203, 2003.

FERREIRA, A. M. Gestão da satisfação e fidelidade do cliente: um estudo dos fatores que influenciam a satisfação e a fidelidade no turismo regional. Dissertação (Mestrado em Ciências em Engenharia de Produção) - Universidade Federal do Rio Grande do Norte, Natal, 2004.

GALLARZA, M. G.; GIL SAURA, I. Value dimensions, perceived value, satisfaction and loyalty: an investigation of university students' travel behaviour. Tourism Management, v. 27, n. 3, p. 437-452, 2006.

GONZÁLEZ, M. O. A. Gestão de Satisfação e Fidelidade do Cliente na Hotelaria:Um Estudo Sobre os Fatores que Influenciam a Satisfação e a Fidelidade do Turista Internacional no Brasil. Dissertação (Mestrado em Ciências em Engenharia de Produção) - Universidade Federal do Rio Grande do Norte, Natal, 2005.

GREENE, W. H.; HENSHER, D. A. Modeling Ordered Choices: A Primer. Cambridge: Cambridge University Press, 2010.

HASEGAWA, H. Analyzing tourists' satisfaction: a multivariate ordered probit approach. Tourism Management, v. 31, n. 1, p. 86-97, 2010.

HUI, T. K.; WAN, D.; HO, A. Tourists' satisfaction, recommendation and revisiting Singapore. Tourism Management, v. 28, n. 4, p. 965-975, 2007.

HYUN, S. S.; PERDUE, R. R. Previous trip satisfaction, destination images, and probability of future visitation. Tourism Analysis, v. 15, n. 6, p. 725-728, 2010.

JANG, S.; FENG, R. Temporal destination revisit intention: the effects of novelty seeking and satisfaction. Tourism Management, v. 28, n. 2, p. 580-590, 2007.

JOÃO, I. S.; MERLO, E. M.; MORGADO, R. R. Análise dos atributos valorizados pelo consumidor de hotelaria do segmento econômico: um estudo exploratório. Turismo Visão e Ação, v. 12, n. 1, p. 4 22, 2010.

LEMOS, S. F. Fatores Indutores da Fidelidade do Turista aos Hotéis na Cidade de Gramado no Rio Grande do Sul. Dissertação (Mestrado em Turismo e Hotelaria) - Universidade do Vale do Itajaí, Balnerário Camboriú, 2001.

LITVIN, S. W.; GOLDSMITH, R. E.; PAN, B. Electronic word-of-mouth in hospitality and tourism management. Tourism Management, v. 29, n. 3, p. 458-468, 2008.

MACHADO, D. F. C.; GOSLING, M. A imagem do destino turístico Ouro Preto e seus reflexos na lealdade, na satisfação e na divulgação boca a boca. Observatório de Inovação do Turismo, v. 5, n. 3, p., 2010.

MARCUSSEN, C. H. Determinants of tourist satisfaction and intention to return. Tourism, v. 59, n. 2, p. 203-221, 2011.

MCDOWALL, S.; MA, E. An analysis of tourists' evaluation of Bangkok's performance, their satisfaction, and destination loyalty: comparing international versus domestic Thai tourists. Journal of Quality Assurance in Hospitality \& Tourism, v. 11, n. 4, p. 260-282, 2010. 
MELO, A. A. D.; FARIAS, J. S. O setor turístico de hospitalidade: um estudo do perfil do dirigente de pousadas e da satisfação gerada por este tipo de empreendimento. Turismo Visão e Ação, v. 5, n. 3, p. 287-302, 2003.

MENDES, J. D. C. et al. The tourist experience: exploring the relationship between tourist satisfaction and destination loyalty. Tourism (13327461), v. 58, n. 2, p. 111-126, 2010.

MENEZES, A. G. D.; VIEIRA, J. C.; CARVALHO, J. Assessing tourist satisfaction in the Azores: a microeconometric approach. European Journal of Tourism Research, v. 2, n. 1, p. 91-122, 2009.

MENEZES, V. O. A importância do atendimento para a satisfação do turista: estudo de caso dos quiosques na Ilha de Porto Belo - SC. Caderno Virtual de Turismo, v. 9, n. 3, p. 121-135, 2009.

MINCIOTTI, S. A.; SANTOLIA, F.; KASPAR, C. A. R. P. Identificação de fatores críticos de sucesso para monitoramento. Turismo em Análise, v. 19, n. 1, p. 155-173, 2008.

MINISTÉRIO DO TURISMO. Estudo da demanda turística internacional: 2005-2011. Brasília: Ministério do Turismo, 2012.

MOTTA, G. D. S.; LIMA, M. C. Indicações para a gestão da qualidade em serviços turísticos para consumidores da terceira idade: uma análise qualitativa com a interface Panteon. Caderno Virtual de Turismo, v. 7, n. 1, p., 2007.

OLIVEIRA, T. V. D.; IKEDA, A. A. Agências de turismo: oferta de serviços e satisfação do cliente. Turismo em Análise, v. 13, n. 2, p. 35-47, 2002.

OZTURK, A. B.; HANCER, M. Exploring destination satisfaction: a case of Kizkalesi, Turkey. Tourism Analysis, v. 13, n. 5/6, p. 473-484, 2008.

PETRICK, J. F.; BACKMAN, S. J. An examination of the determinants of golf travelers' satisfaction. Journal of Travel Research, v. 40, n. 3, p. 252-258, 2002.

PRAYAG, G. Image, satisfaction and loyalty - the case of Cape Town. Anatolia: An International Journal of Tourism \& Hospitality Research, v. 19, n. 2, p. 205-224, 2008.

PREBENSEN, N.; SKALLERUD, K.; CHEN, J. S. Tourist motivation with sun and sand destinations: satisfaction and the wom-effect. Journal of Travel \& Tourism Marketing, v. 27, n. 8, p. 858-873, 2010.

REIS NETO, M. T.; GONÇALVES FILHO, C.; CABRAL, L. M. Antecedentes da lealdade - um estudo exploratório em hotelaria para negócios. Turismo Visão e Ação, v. 11, n. 1, p. 76-91, 2009.

RODRIGUES, J. M. S. Gestão da satisfação e da fidelidade: um estudo dos fatores que afetam a satisfação e a fidelidade no mercado de turismo (Mestrado) - UFRN, 2003.

SALAZAR, V. S.; FARIAS, S. A. D.; LUCIAN, R. Emoção, ambiente e sabores: a influência do ambiente de serviços na satisfação de consumidores de restaurantes gastronômicos. Observatório de Inovação do Turismo, v. 3, n. 4, p., 2008.

SALAZAR, V. S.; FARIAS, S. A. D.; LUCIAN, R. O papel das pessoas nos ambientes de restaurantes gastronômicos e a satisfação do cliente. Turismo Visão e Ação, v. 11, n. 3, p. 325-340, 2009.

SANTOS, G. E. D. O.; VASSALLO, M. D.; RABAHY, W. A. Determinantes do valor percebido e da intenção de retorno no turismo receptor brasileiro. Revista Brasileira de Pesquisa em Turismo, v. 3, n. 3, p. 34-56, 2009.

SILVA, L. M. T. D.; MEDEIROS, C. A. F.; COSTA, B. K. Qualidade dos serviços turísticos no setor de restaurantes: uma aplicação do modelo SERVPERF. Revista Hospitalidade, v. 6, n. 2, p. 115-139, 2009. 
SOUTO, C. D. M. R.; OLIVEIRA, L. M. B. D. Ter funcionários satisfeitos é ter clientes satisfeitos: realidade ou indícios? um estudo em agências de viagens. Observatório de Inovação do Turismo, v. 2, n. 2, p., 2007.

TASCI, A. D. A.; BOYLU, Y. Cultural comparison of tourists' safety perception in relation to trip satisfaction. International Journal of Tourism Research, v. 12, n. 2, p. 179-192, 2010.

TURNER, L. W.; REISINGER, Y. V.; MCQUILKEN, L. How Cultural Differences Cause Dimensions of Tourism Satisfaction. Journal of Travel \& Tourism Marketing, v. 11, n. 1, p. 79-101, 2002.

UNWTO. UNWTO World Tourism Barometer. Madrid: UNWTO, 2012.

VASCONCELOS, P. N. M. D. Pesquisa de mercado: uma análise do grau de satisfação dos ecoturistas em relação à compra dos produtos artesanais das RDS Mamirauá e Amanã. Caderno Virtual de Turismo, v. 7, n. 1, p. 31-40, 2007.

VEIGA, L. S.; FARIAS, J. S. Avaliação da qualidade dos serviços em uma pousada com a aplicação da escala Servqual. Turismo Visão e Ação, v. 7, n. 2, p. 257-272, 2005.

YOON, Y.; UYSAL, M. An examination of the effects of motivation and satisfaction on destination loyalty: a structural model. Tourism Management, v. 26, n. 1, p. 45-56, 2005.

ZUCCO, F. D.; MAGALHÃES, M. D. R. A.; MORETTI, S. L. D. A. Análise do nível de satisfação dos participantes: evidências das últimas três edições da Oktoberfest em Blumenau (2006, 2007 e 2008). Turismo Visão e Ação, v. 12, n. 3, p. 331-347, 2010.

\section{Recebido em: 10/09/2012 (1 ${ }^{\text {a }}$ versão $)$ 11/05/2013 ( $2^{\mathrm{a}}$ versão $)$ \\ Aprovado em: 05/08/2013}

